\title{
A Theoretical Study on the Stability, Reactivity and Protonic Affinity of 2-Phenylbenzothiazole Derivatives
}

\author{
Bede Affoue Lucie ${ }^{1,}$, , Kone Soleymane ${ }^{1}$, N'Guessan Boka Robert ${ }^{1}$, Yapo Kicho Denis ${ }^{1}$, \\ Ziao Nahosse ${ }^{2}$ \\ ${ }^{1}$ Unit Formation and Research of Sciences of Structures of Matter and Technology (UFR SSMT), University Felix Houphouët-Boigny, \\ Abidjan, Ivory Coast \\ ${ }^{2}$ Unit Formation and Research of Sciences Fondamental and Applied (UFR SFA), University Nangui Abrogoua, Abidjan, Ivory Coast
}

\author{
Email address: \\ lucie.bede@univ-fhb.edu.ci (B. A. Lucie) \\ *Corresponding author
}

\section{To cite this article:}

Bede Affoue Lucie, Kone Soleymane, N'Guessan Boka Robert, Yapo Kicho Denis, Ziao Nahosse. A Theoretical Study on the Stability, Reactivity and Protonic Affinity of 2-Phenylbenzothiazole Derivatives. Modern Chemistry. Special Issue: Advanced Journal of Chemistry. Vol. 7, No. 3, 2019, pp. 65-72. doi: 10.11648/j.mc.20190703.14

Received: May 28, 2019; Accepted: September 20, 2019; Published: September 29, 2019

\begin{abstract}
The 2-phenylbenzothiazole derivatives have antitumor activities. Work has shown that these derivatives have mesomeric forms. The electrophilic centers of these mesomers form adducts with the nucleophilic centers of deoxyribonucleic acid (DNA). These adducts destroy the tumor cells and prevent the proliferation of these. In this sense, the knowledge of electrophilic sites, nucleophiles and the capacity to protonate these derivatives is therefore useful if we want to know their future in the biological environment. Using DFT/B3LYP method associated with the bases 6-31G (d, p) and 6-31+G (d, p), this work aims at determining the preferential protonation site, the electrophilic and nucleophilic centers of six 2-phenylbenzothiazole. This study also analyzes the stability of these derivatives. Calculations are carried out in gas and aqueous phases. Results show that fluorinated derivatives are the most stable. 2-(4-aminophenyl) benzothiazoles are the most reactive. The atoms carbon $\mathrm{C}^{4}, \mathrm{C}^{5}$ and $\mathrm{C}^{6}$ of benzothiazole ring are the most electrophilic. Interactions of these derivatives with nucleophilic centers of deoxyribonucleic acid (DNA) will probably be at these atoms. Nitrogen $\mathrm{sp}^{2}(\mathrm{~N} 1)$ of benzothiazole ring remains the most nucleophilic center and the preferential site of protonation in all the molecules studied. These results highlight the influence of the substituents on the basicity of the nitrogen $\mathrm{sp}^{2}(\mathrm{~N} 1)$ and reactivity of the 2-phenylbenzothiazole derivatives studied.
\end{abstract}

Keywords: 2-Phenylbenzothiazole, Energetic Gaps, Fukui Indices, Protonic Affinity, DFT/B3LYP

\section{Introduction}

Cancers constitute on planetary scale a public health concern. If the epidemiological data show a decrease in mortality rate linked to this pathology in Western countries, these are expanding in developing countries [1-5]. Scientific studies have shown that the most common cancers in the sub-Saharan region are prostate, cervical, breast, ovarian and liver cancers $[1,5]$. Treatment of this disease is a challenge for both doctor and chemist. So, many studies are conducted on search for new anticancer molecules to eradicate these pathologies. It was in this context that anticancer activity of certain benzothiazole derivatives were discovered.
Benzothiazoles have various biological properties [6-8]. Because of their biological potential, these compounds are synthesized for various pharmaceutical uses [6, 9-11]. Structure of 2-phenylbenzothiazole (Figure 1) represents the pharmacophore of a series of molecules that have anti-tumor activities against kidney, breast, lung and ovarian cancers [12-18]. Studies have shown that 2-phenylbenzothiazole derivatives have a very interesting anticancer activity $[13,15$, 19-25].

Capacity to protonate and reactivity of a bioactive molecule is likely to affect its fate in biological environment. Bioactive molecules are usually polyfunctional derivatives. Therefore, study of reactivity and determination of protonation sites of these bioactive molecules are necessary if we want to know their fate in biological environment. 
However, in search for solution to health problem related to cancers, most of the research is focused on synthesis and effectiveness of the anticancer molecules used in treatment of these pathologies.

By implementing quantum chemistry methods, this work aims to determine preferential protonation sites of six 2phenylbenzothiazole derivatives (Figure 1). A study of the stability and reactivity of these derivatives is carried. This work also examines the tautomeric equilibrium possible that may exist in these molecules. In this sense, a theoretical calculation of thermodynamic energies and reactivity parameters is performed. Determination of protonation sites and the prediction of acidity is made from the calculation of protonic affinity (PA) and basicity (GB). Calculation of Fukui indices made it possible to identify electrophilic and nucleophilic sites of molecules studied. Hybrid functional B3LYP of Density Functional Theory (DFT) method associated with bases $6-31 \mathrm{G}(\mathrm{d}, \mathrm{p})$ and $6-31+\mathrm{G}(\mathrm{d}, \mathrm{p})$ is used to conduct this study. Calculations are carried in gas and aqueous phases.

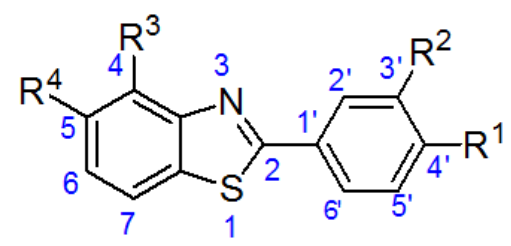

Figure 1. Structures of 2-phenylbenzothiazole derivatives with atoms numbers.

BTa: $\mathrm{R}^{1}=\mathrm{NH}_{2}, \mathrm{R}^{2}=\mathrm{CH}_{3}, \mathrm{R}^{3}=\mathrm{R}^{4}=\mathrm{H}$

BTd: $\mathrm{R}^{1}=\mathrm{OCH}_{3}, \mathrm{R}^{2}=\mathrm{OCH}_{3}, \mathrm{R}^{3}=\mathrm{R}^{4}=\mathrm{H}$

BTb: $\mathrm{R}^{1}=\mathrm{NH}_{2}, \mathrm{R}^{2}=\mathrm{CH}_{3}, \mathrm{R}^{3}=\mathrm{F}, \mathrm{R}^{4}=\mathrm{H}$

BTe: $\mathrm{R}^{1}=\mathrm{OCH}_{3}, \mathrm{R}^{2}=\mathrm{OCH}_{3}, \mathrm{R}^{3}=\mathrm{F}, \mathrm{R}^{4}=\mathrm{H}$

BTc: $\mathrm{R}^{1}=\mathrm{NH}_{2}, \mathrm{R}^{2}=\mathrm{CH}_{3}, \mathrm{R}^{3}=\mathrm{H}, \mathrm{R}^{4}=\mathrm{F}$

BTf: $\mathrm{R}^{1}=\mathrm{NH}_{2}, \mathrm{R}^{2}=\mathrm{CH}_{3}, \mathrm{R}^{3}=\mathrm{H}, \mathrm{R}^{4}=\mathrm{F}$

\section{Materials and Method}

\subsection{Calculation Level}

Density Functional Theory (DFT) [26, 27] with the hybrid functional B3LYP $[28,29]$ associated with bases 6-31G (d, p) and $6-31 G+(d, p)$ was used to perform calculations. The calculation software used is the Gaussian 03 quantum chemistry software [30]. Calculs are carried out in gas and aqueous phases at temperature of 298 Kelvin and at pressure of 1 atmosphere (1 atm). Polarized Continuum Model (PCM) [31] is taken as a solvation model. Previous theoretical work on prediction of acidity has shown that hybrid functionals such as B3LYP associated with bases $6-31+G(d, p)$, 6$311+\mathrm{G}(\mathrm{d})$ and $6-311+\mathrm{G}(3 \mathrm{df}, 3 \mathrm{pd})$ lead to results in good agreement with experimental data [32-34]. Protonic affinities and basicity were therefore determined from geometry optimization at the B3LYP/6-31+G (d, p) theory level.

\subsection{Global and Local Indices Derived from Conceptual DFT}

Density Functional Theory (DFT) has defined a number of physico-chemical quantities such as electronegativity $(\chi)$, hardness $(\eta)$, global softness $(S) \ldots$ Thus for a system with $\mathrm{N}$ electrons, electronic energie total $\mathrm{E}$ and potential energie $\mathrm{V}$ $(r)$, the chemical potential $(\mu)$ is defined as first derivative of $\mathrm{E}$ with respect to $\mathrm{N}$ for $\mathrm{V}(\mathrm{r})$ constant [35]. These reactivity parameters can also be expressed as a function of Ionization Potential (IP) and Electronic Affinity (EA) from following relationships:

$$
\begin{gathered}
\mu=-\frac{P I+A E}{2}=-\chi \\
\eta=\frac{1}{S}=(P I-A E) / 2 \\
\omega=\frac{\mu^{2}}{2 \eta}=\frac{\chi^{2}}{2 \eta} \\
P I=-\varepsilon_{\text {HомO }} \text { et } A E=-\varepsilon_{L U M O}
\end{gathered}
$$

$\varepsilon_{\text {HOMO }}$ and $\varepsilon_{L U M O}$ are respectively energies of HOMO and LUMO frontier molecular orbitals. Functions Fukui are obtained using procedure based on finite difference method [36-38]. The different values of these local descriptors are calculated from equations (4), (5) and (6).

$$
\begin{gathered}
f_{k}^{+}=q_{k}(N+1)-q_{k}(N) \\
f_{k}^{-}=q_{k}(N)-q_{k}(N-1) \\
\Delta f=f_{k}^{+}-f_{k}^{-}
\end{gathered}
$$

$q_{k}(N), q_{k}(N+1)$ and $q_{k}(N-1)$ are respectively the electronic population of the atom $\mathrm{k}$ in neutral molecule, anionic molecule and cationic molecule. $\Delta f$ is the dual descriptor. It is a representative function of reactivity of molecule. Positive or negative value of this function indicates respectively an electrophilic zone or a nucleophilic zone.

\subsection{Protonic Affinity and Basicity}

Protonation is a process in which a Lewis B base fixes a proton to give a protonated molecule $\mathrm{BH}^{+}$according to equation below (Figure 2):

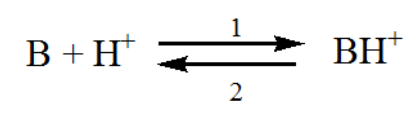

Figure 2. Protonation equilibrium equation.

Protonic affinity (PA) and basicity (GB) are respectively the opposite of enthalpy variation and free enthalpy of protonation reaction in the forward direction (1). They are calculated from relations (7) and (8):

$$
\begin{gathered}
P A=-\Delta_{r} H_{1}=\Delta_{f} H(B)+\Delta_{f} H\left(H^{+}\right)-\Delta_{f} H\left(B H^{+}\right) \\
G B=-\Delta_{r} G_{1}=\Delta_{f} G(B)+\Delta_{f} G\left(H^{+}\right)-\Delta_{f} G\left(B H^{+}\right)
\end{gathered}
$$

Enthalpy and free enthalpy of proton formation in literature $[39,40]$ are as follows:

$$
\Delta_{f} H\left(H^{+}\right)=+367,2 \mathrm{Kcal} . \mathrm{mol}^{-1}
$$




$$
\Delta_{f} G\left(H^{+}\right)=-6,29 \text { Kcal. } \mathrm{mol}^{-1}
$$

\section{Results and Discussion}

Results concern stability, tautomerism, reactivity of 2phenylbenzothiazole derivatives and protonic affinity of its heteroatoms.

\subsection{Relative Stability}

\subsubsection{Stability of 2-phenylbenzothiazole Derivatives}

The different molecular structures of 2phenyllbenzothiazole derivatives studied, differ from each other by the position of the fluor atom $(\mathrm{F})$ and by the substitutions on the phenyl group in position 2 of benzothiazole (Figure 1). Values of energies of enthalpy and free enthalpy of molecules are regrouped in Table 1.

$$
\Delta_{f} G^{\circ}(\mathrm{BTa})>\Delta_{f} G^{\circ}(\mathrm{BTb})>\Delta_{f} G^{\circ}(\mathrm{BTc})>\Delta_{f} G^{\circ}(\mathrm{BTd})>\Delta_{f} G^{\circ}(\mathrm{BTe})>\Delta_{f} G^{\circ}(\mathrm{BTf})
$$

This ranking gives the order of increasing relative stability that follows:

$$
\mathrm{BTa}<\mathrm{BTb}<\mathrm{BTc}<\mathrm{BTd}<\mathrm{BTe}<\mathrm{BTf}
$$

This stability sequence shows that BTc derivative is more stable than the BTb; and the BTf more stable than BTe. This indicates that the fluor atom at the position 5 increases stability of 2-phenylbenzothiazole. These values also show that substitution of methyl $\left(\mathrm{CH}_{3}\right)$ and amine $\left(\mathrm{NH}_{2}\right)$ groups by methoxyl $\left(\mathrm{CH}_{3} \mathrm{O}\right)$ confers a greater stability to derivatives BTd, BTe and BTf.

\subsubsection{Stability of Tautomers}

To evaluate the tautomerism of 2-(4aminophenyl)benzotiazole derivatives (BTa, BTb and BTc), we first consider possible equilibriums between the potential tautomers and then we calculate equilibrium constants. Most therapeutic activities of biological molecules depend on potential equilibriums between their tautomeric forms [41]. For this fact, we have studied possible equilibrium that can exist between these molecules (Figure 3). Each molecule can be in the form of two tautomers: tautomers amine and imine. Values of the thermodynamic energies, energetic gaps and dipole moment of tautomers are summarized in Tables 2 and 3.

Table 2. Enthalpy, Gibbs free energies (kJ.mol-1), energy gaps (eV) and dipole moment (Debye) of tautomers calculated at B3LYP/6-31G $(d, p)$ in gas phase.

\begin{tabular}{lllll}
\hline Tautomers & $\boldsymbol{\Delta}_{\boldsymbol{f}} \boldsymbol{H}^{\circ}$ & $\boldsymbol{\Delta}_{\boldsymbol{f}} \boldsymbol{G}^{\circ}$ & $\boldsymbol{\Delta} \mathbf{E}(\mathbf{e V})$ & $\boldsymbol{\mu}$ \\
\hline BTa-amine & -2980.8 & -4046.1 & 4,11 & 3,26 \\
BTa-imine & -2968.4 & -4034.5 & 3.19 & 6.20 \\
BTb-amine & -3172.1 & -4242.5 & 4,09 & 3,68 \\
BTb-imine & -3158.4 & -4230.1 & 3.21 & 6.06 \\
BTc-amine & -3180.3 & -4250.7 & 4,04 & 4,77 \\
BTc-imine & -3169.5 & -4236.5 & 3.17 & 6.71 \\
\hline
\end{tabular}

Table 1. Gibbs free energies and enthalpies (kJ.mol $\left.{ }^{-1}\right)$ of 2phenylbenzothiazole derivatives calculated at the B3LYP/6-31G $(d, p)$ in gas phase.

\begin{tabular}{lll}
\hline Molecules & $\Delta_{\boldsymbol{f}} \boldsymbol{H}^{\circ}$ & $\Delta_{\boldsymbol{f}} \boldsymbol{G}^{\circ}$ \\
\hline BTa & -2980.8 & -4046.1 \\
BTb & -3172.1 & -4242.5 \\
BTc & -3180.3 & -4250.7 \\
BTd & -4736.9 & -5914.8 \\
BTe & -4927.5 & -6112.9 \\
BTf & -4935.8 & -6121.1 \\
\hline
\end{tabular}

All energies are negative (Table 1). These negative values of enthalpy and free enthalpy translate the formation and the existence of these compounds at temperature of $298 \mathrm{~K}$ and at 1 atmosphere $(\mathrm{P}=1 \mathrm{~atm})$. Gibbs free energy, at computational level B3LYP/6-31G (d, p), helps to discuss relative stability of 2-phenylbenzothiazole derivatives shown in Figure 1. Considering Gibbs free energy values grouped in Table 1, we deduce descending order of values of $\Delta_{f} G^{\circ}$ as follows:

Table 3. Reaction themodynamic energies $\left(\mathrm{kJ}^{\mathrm{m}} \mathrm{mol}^{-1}\right)$, and equilibrium constants of tautomers calculated at B3LYP/6-31G (d, p) in gas phase.

\begin{tabular}{lllll}
\hline Equilibrium & $\Delta_{\boldsymbol{r}} \boldsymbol{H}$ & $\Delta_{\boldsymbol{r}} \boldsymbol{G}$ & $\mathbf{K}_{\mathrm{eq} 1}$ & $\mathbf{K}_{\mathrm{eq} 2}$ \\
\hline 1 & 12.4 & 11.6 & $9,38.10^{-3}$ & $1,06.10^{2}$ \\
2 & 13.7 & 12.4 & $6,86.10^{-3}$ & $1,46.10^{2}$ \\
3 & 10.8 & 14.2 & $3,28.10^{-3}$ & $3,05.10^{2}$ \\
\hline
\end{tabular}

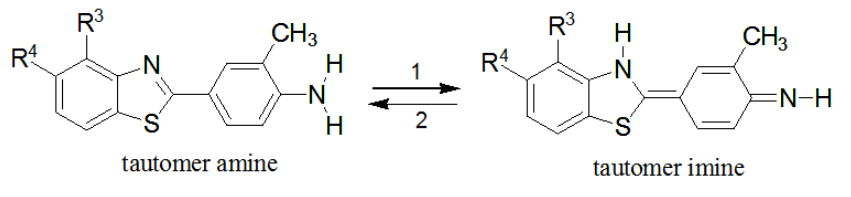

Figure 3. Possible equilibrium between tautomers of 2-(4aminophenyl)benzothiazole derivatives.

Equilibrium 1: $\mathrm{R}^{3}=\mathrm{R}^{4}=\mathrm{H}$

Equilibrium 2: $\mathrm{R}^{3}=\mathrm{F}, \mathrm{R}^{4}=\mathrm{H}$

Equilibrium 3: $\mathrm{R}^{3}=\mathrm{H}, \mathrm{R}^{4}=\mathrm{F}$

Results in Table 2 show that tautomers imine have the highest thermodynamic energy values. They also have lowest values of energy gaps. Which means that tautomer amine is more stable than tautomer imine. Values of reaction enthalpie and free enthalpie reaction are positive. These positive values of thermodynamic energies reaction reflect a nonspontaneous endothermic reaction under conditions of this study. Tautomeric equilibrium of these derivatives is nonspontaneous reaction at $298 \mathrm{~K}$. A chemical equilibrium between two tautomers A and B (Figure 4) is characterized by its equilibrium constant $\mathrm{K}_{\mathrm{eq}}$.

\section{$\mathrm{A} \longrightarrow \mathrm{B}$ \\ Figure 4. Equilibrium between two tautomers $A$ and $B$.}

Calculation of $\mathrm{K}_{\mathrm{eq}}$ makes it possible to highlight existence tautomeric equilibrium. $\mathrm{K}_{\mathrm{eq}}$ 's values are obtained at $298 \mathrm{~K}$ with the relation: 


$$
K_{e q}=\exp ^{\left(-\Delta_{r} G(T) / R T\right)}
$$

When $\mathrm{K}_{\mathrm{eq}}<10^{-4}$, the form $\mathrm{A}$ exists alone. If $\mathrm{K}_{\mathrm{eq}}>10^{4}$, compound $\mathrm{B}$ predominates. The equilibrium becomes effective if $\mathrm{K}_{\text {eq }}$ ranging from $10^{-4}$ to $10^{4}$.

Values of the equilibrium constants calculated for these molecules are between $10^{-4}$ and $10^{4}$ (Table 3 ). This indicates that the studied systems are in a tautomeric equilibrium state. These molecules can exist under tautomers.

Tautomers imine have higher dipole moment values. They are therefore more polar than tautomers amine. Imine function increases polarity of 2-(4aminophenyl)benzothiazoles studied.

\subsection{Reactivity of 2-Phenylbenzothiazole Derivatives}

\subsubsection{Frontier Molecular Orbitals Theory (FMO Therory)}

The energy gap between the HOMO and LUMO frontier molecular orbitals is a critical parameter in the determination of molecular electrical transport properties as it measures the electronic conductivity. It makes it possible to characterize the chemical reactivity and the kinetic stability of the molecule. A molecule with a small energy gap is generally associated with high chemical reactivity, low kinetic stability, and is also called a soft molecule [42, 43]. The energies of the frontier molecular orbitals (HOMO, LUMO) and energy gaps calculated in this work are summarized in Table 4.

Table 4. Energies of frontier molecular orbitals (HOMO, LUMO) and energy gaps $(\mathrm{eV})$ calculated at B3LYP/6-31G (d, p) level in gas and aqueous phases.

\begin{tabular}{lllllll}
\hline \multirow{2}{*}{ Molecules } & \multicolumn{2}{l}{ gas Phase } & \multicolumn{4}{c}{ aqueous Phase } \\
\cline { 2 - 7 } & $\boldsymbol{\varepsilon}_{\text {Hомо }}$ & $\boldsymbol{\varepsilon}_{\text {LUMO }}$ & $\boldsymbol{\Delta E}$ & $\boldsymbol{\varepsilon}_{\text {HOMO }}$ & $\boldsymbol{\varepsilon}_{\text {LUMO }}$ & $\boldsymbol{\Delta E}$ \\
\hline BTa & -5.305 & -1.195 & 4.110 & -5.413 & -1.441 & 3.972 \\
BTb & -5.376 & -1.289 & 4.087 & -5.449 & -1.505 & 3.944 \\
BTc & -5.401 & -1.358 & 4.044 & -5.445 & -1.544 & 3.901 \\
BTd & -5.645 & -1.386 & 4.258 & -5.810 & -1.611 & 4.200 \\
BTe & -5.727 & -1.482 & 4.245 & -5.861 & -1.677 & 4.184 \\
BTf & -5.740 & -1.547 & 4.193 & -5.849 & -1.711 & 4.138 \\
\hline
\end{tabular}

The Highest Occupied Molecular Orbital (HOMO) and Lowest Unoccupied Molecular Orbital (LUMO) determine interaction for molecule with other species. Molecular orbital HOMO reflects electro-donor (nucleophilic) character of molecule. Higher the energy of this orbital, the more easily the molecule will give up electrons. As for LUMO, it reflects electro-acceptor (electrophile) character of molecule. The lower the energy of this molecular orbital, the easier the molecule will accept electrons. The BTa molecule has the highest HOMO level energy (table 4). This molecule will be susceptible to electrophilic attack. The lowest energy level LUMO is obtained with the molecule BTf. This molecule would be favorable to a nucleophilic attack.

Energetic gaps drop in aqueous phase. Reactivity of molecules increases in aqueous phase. Values of $\Delta \mathrm{E}$ mentioned in Table 4 are smaller in the first group of molecules (derivatives having as basic structure the molecule $\mathrm{P} 1$, Figure 5). The smallest value of $\Delta \mathrm{E}$ is obtained with benzothiazole BTc. The BTd molecule has the largest
HOMO-LUMO difference. This leads us to conclude that substitution of methyl and amine groups in 3' and 4' positions by methoxyl leads to an increase in HOMO-LUMO energetic gap. This substituent increases stability of benzothiazoles studied. This makes them less reactive. Also, fluor atom on benzothiazole causes a decrease in energetic gap. This translates that fluorinated 2-phenylbenzothiazoles are more reactive.

\subsubsection{Global Indices of Reactivity}

To understand different aspects of molecular reactivity, several descriptors of chemical reactivity are proposed. Reactivity parameters examined in this serie of molecules are: chemical potential ( $\mu$ pot), hardness $(\eta)$, softness $(S)$ and electrophile index $(\omega)$. The study of reactivity according to the Frontier Molecular Orbitals theory has shown that molecules studied are more reactive in aqueous phase. We have therefore retained data obtained in this phase for the analysis of global indices of reactivity. Calculated values of these parameters are reported in Table 5.

Table 5. Chemical potential, hardness, electrophilia (eV) and softness $(\mathrm{eV})^{-1}$ calculated in aqueous phase at B3LYP/6-31G (d, p).

\begin{tabular}{lllll}
\hline Molecules & $\boldsymbol{\mu}_{\text {pot }}$ & $\boldsymbol{\eta}$ & $\boldsymbol{S}$ & $\boldsymbol{\omega}$ \\
\hline BTa & -3.427 & 3.972 & 0.252 & 1.478 \\
BTb & -3.477 & 3.944 & 0.254 & 1.533 \\
BTc & -3.495 & 3.901 & 0.256 & 1.566 \\
BTd & -3.711 & 4.199 & 0.238 & 1.640 \\
BTe & -3.780 & 4.138 & 0.242 & 1.726 \\
BTf & -3.769 & 4.184 & 0.239 & 1.698 \\
\hline
\end{tabular}

Electrophilia $(\omega)$ is a reactivity parameter that accounts for electrophilic caracter of a molecular system. Also, the higher the value of this parameter, the more important will be reactivity of molecule with a nucleophile. Values of this reactivity parameter calculated for these compounds (Table 5) show that BTa, BTb and BTc derivatives are the least electrophilic. Methoxylated derivatives have the highest values of electrophilia. This indicates that methoxylated benzothiazoles are the most apt to receive electrons. These data show that methoxyl substituent contributes to increase this reactivity index. Also, we note that fluorinated molecules are the most electrophilic. Fluor atom in position 5 contributes to accentuate this electrophilic character.

Chemical hardness $(\eta)$ and overall softness $(S)$ express the strength of a molecular system, whether gain or loss of electrons (charge transfer). In a series of molecules, when the value of $\eta$ is small, the molecule is soft; and when it is large, molecule is hard. Data in Table 4 show that BTa, BTb and BTc derivatives have the lowest values of hardness. These molecules are the softest, therefore the most reactive.

\subsubsection{Local Indices of Reactivity: Fukui Indices}

Work has shown that the 2-(4-aminophenyl) benzothiazole derivatives have mesomeric forms. Electrophilic centers of these mesomers form adducts with the nucleophilic centers of DeoxyriboNucleic Acid (DNA). These adducts destroy tumor cells and prevent proliferation of these cells $[44,45]$. Given results of these 
studies, it is important to determine sites of interaction (nucleophilic and electrophilic) of these molecules. Calculations of Fukui indices are necessary for the determination of these interaction sites. Determination of these interaction sites concerned 2-(4-aminophenyl) benzothiazole derivatives that are $\mathrm{BTa}, \mathrm{BTb}$ and $\mathrm{BTc}$ molecules. Atoms involved in this study are the nine atoms of benzothiazole ring (Figure 1). Fukui indices were calculated using Hirschfeld populations [46]. Results of calculations are summarized in Table 6.

Table 6. Fukui indices calculated at B3LYP/6-31+G(d) level in gas phase.

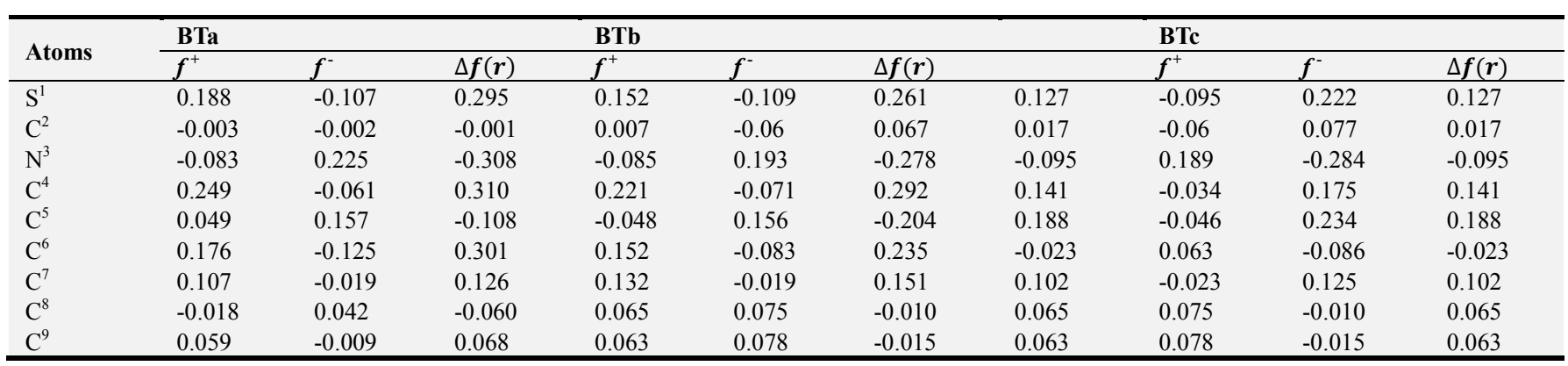

A positive value of $\Delta f(r)$ indicates an electrophilic region. A nucleophilic site gives a negative value of $\Delta f(r)$. In the BTa molecule, this reactivity parameter has a positive value at atoms $\mathrm{S}^{1}, \mathrm{C}^{4}, \mathrm{C}^{6}, \mathrm{C}^{7}$ and $\mathrm{C}^{9}$ level (Table 6). These atoms are electrophilic sites. A nucleophilic attack would probably occur at these atoms level. Carbons $\mathrm{C}^{4}$ and $\mathrm{C}^{6}$ have the highest values of $\Delta f(r)$. These would be more reactive vis-à-vis a nucleophilic attack. atoms $\mathrm{N}^{3}, \mathrm{C}^{5}$ and $\mathrm{C}^{8}$ have negative $\Delta f(r)$ values. These atoms are nucleophilic centers. BTb and BTc derivatives have virtually the same electrophilic and nucleophilic sites. Atoms $\mathrm{S}^{1}, \mathrm{C}^{2}, \mathrm{C}^{4}, \mathrm{C}^{6}$ and $\mathrm{C}^{7}$ of $\mathrm{BTb}$ derivative have positive values of $\Delta f(r)$. With molecule BTc, it is atoms $\mathrm{S}^{1}$, $\mathrm{C}^{2}, \mathrm{C}^{4}, \mathrm{C}^{5}, \mathrm{C}^{7}$ which have positive values of $\Delta f(r)$. Atoms $\mathrm{N}^{3}, \mathrm{C}^{5}, \mathrm{C}^{8}, \mathrm{C}^{9}$ and $\mathrm{N}^{3}, \mathrm{C}^{6}, \mathrm{C}^{8}, \mathrm{C}^{9}$ of $\mathrm{BTb}$ and BTc derivatives, respectively, have negative values of $\Delta f(r)$. These atoms are nucleophilic sites. Nitrogen $\mathrm{N}^{3}$ has the lowest value of $\Delta f(r)$ and the maximum value of $f^{-}$in the compounds studied. An electrophilic attack would be made primarily on this atom (N3). For all derivatives studied, carbons $\mathrm{C}^{4}, \mathrm{C}^{5}$ and $\mathrm{C}^{6}$ would be the most reactive vis-à-vis a nucleophilic attack. Interactions of 2-(4aminophenyl) benzothiazole derivatives studied with the nucleophilic centers of DNA will probably occur at these atoms.

\subsection{Protonic Affinity and Basicity}

Values of Protonic Affinity (PA) and Basicity (GB) are given in Table 7. The protonated sites are shown in Figure 5. These are the nitrogen atoms $\mathrm{sp}^{2}$ of benzothiazole ring (N1) and $\mathrm{sp}^{3}$ of amine substituent at position $4^{\prime}$ of phenyl group (N2). Molecules BTa, BTb and BTc have same pharmacophore noted P1 (2-(4-aminophenyl) benzothiazole derivatives). BTd, BTe and BTf derivatives have base structure P2 (2- (4-methoxyphenyl) benzothiazole derivatives). Protonation sites for this second group of molecules are atom nitrogen $\mathrm{sp}^{2}$ of benzothiazole denoted $\mathrm{N} 1$ and oxygen atoms of methoxyl groups on positions 4 '(O2) and $3^{\prime}(\mathrm{O} 3)$.

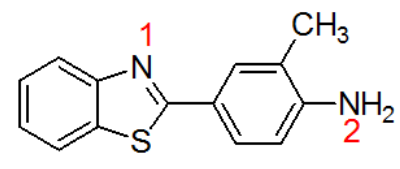

(P1)

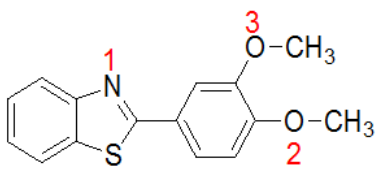

(P2)
Figure 5. Structures of 2-phenylbenzothiazoles with protonated atom numbers; (P1): 2-(4-aminophenyl) benzothiazole, pharmacophore of BTa, BTb and BTc molecules; (P2): 2-(4-methoxyphenyl) benzothiazole, $p$ harmacophore of BTd, BTe and BTf molecules.

Table 7. Protonic affinities and basicities (KJ.mol-1) calculated for atoms selected at B3LYP/6-31+G (d, p) level in gas phase.

\begin{tabular}{|c|c|c|c|c|c|c|c|c|}
\hline \multirow{2}{*}{ Molecules } & \multicolumn{2}{|c|}{$\mathrm{Nsp}^{2}(\mathrm{~N} 1)$} & \multicolumn{2}{|c|}{$\operatorname{Nsp}^{3}(\mathbf{N} 2)$} & \multicolumn{2}{|l|}{01} & \multicolumn{2}{|l|}{$\mathbf{O 2}$} \\
\hline & PA & GB & PA & GB & PA & GB & PA & GB \\
\hline $\mathrm{BTa}$ & 502.1 & 228.97 & 476.6 & 203.96 & & & & \\
\hline $\mathrm{BTb}$ & 500.2 & 227.44 & 475.5 & 202.95 & & & & \\
\hline BTc & 498.5 & 226.43 & 474.7 & 202.33 & & & & \\
\hline BTd & 493.4 & 224.47 & & & 465.4 & 192.48 & 465.9 & 192.98 \\
\hline $\mathrm{BTe}$ & 491.5 & 223.58 & & & 460.2 & 187.14 & 465.3 & 192.43 \\
\hline BTf & 490.3 & 222.17 & & & 459.3 & 186.29 & 464.2 & 191.39 \\
\hline
\end{tabular}

PA and GB both account for basicity strength of a site in molecule. For these six benzothiazoles, these two quantities agree on basicity forces of sites examined. Values of PA and GB of site N1 of BTa, BTb and BTc derivatives are higher than those obtained with nitrogen N2 for same compounds. This site also has the highest value of PA in the BTd, BTe and BTf derivatives. Nitrogen $\mathrm{Nsp}^{2}(\mathrm{~N} 1)$ of benzothiazole ring is therefore preferentiel site of protonation in these molecules. Fluor atom (F) at position 5 causes a decrease in the basicity of sites N1 and N2. Nitrogen N2 remains the least basic. PA and GB values calculated for the $\mathrm{N} 1$ nitrogen are higher in BTa, BTb and BTc molecules compared with those obtained in BTd, BTe and BTf derivatives. Decreasing order of basicity at this site level is: N1 $(\mathrm{BTa})>\mathrm{N} 1(\mathrm{BTb})>\mathrm{N} 1(\mathrm{BTc})>\mathrm{N} 1(\mathrm{BTd})>\mathrm{N} 1(\mathrm{BTe})>\mathrm{N} 1(\mathrm{BTf})$ 
These results indicate that methoxyl groups at positions 3 ' and 4 ' contribute to reducing protonic affinity of site N1. The data also reveal that fluor atom decreases the basicity of sites studied. At level of BTd, BTe and BTf derivatives, PA and GB values of $\mathrm{O} 3$ site are higher than those obtained with $\mathrm{O} 2$ site.

\section{Conclusion}

Results of this theoretical study on 2-phenylbenzothiazole derivatives, have shown that fluorinated derivatives are the most stable. Fluor atom contributes to increasing stability of these molecules. Calculations of equilibrium constants revealed existence of tautomeric equilibrium in 2-(4aminophenyl) benzothiazole derivatives. Examination of stability of tautomers has shown that tautomers amine of these derivatives are the most stable.

The study of reactivity based on calculation of energetic gaps and global indices of reactivity, reveals that 2- (4aminophenyl) benzothiazoles derivatives are the most reactive. fluoro compounds are the most electrophilic. Calculation of Fukui Indices identified nucleophilic and electrophilic sites of 2-(4-aminophenyl)benzothiazole derivatives. These calculs showed that carbons $C^{4}, C^{5}$ and $C^{6}$ are the most electrophilic. Interactions of these derivatives with the nucleophilic centers of deoxyribonucleic acid (DNA) will probably occur at these atoms. Nitrogen N3 remains the most nucleophilic site in all the molecules studied.

Analysis of protonic affinities and basicity (GB) in gas phase, parameters obtained for protonation reactions on target heteroatoms ( $\mathrm{N}$ and $\mathrm{O}$ atoms) shows that 2-(4aminophenyl)benzothiazole derivatives have higher protonic affinities, thus a higher basicity than 2-(4-methoxyphenyl) benzothiazoles derivative. Nitrogen $\mathrm{sp}^{2}$ of benzothiazole ring (N1) is preferentiel site of protonation in all molecules studied. Methoxyl groups at positions 3' and 4' contribute to reducing protonic affinity of nitrogen N1. Data also reveal that fluor atom decreases basicity of sites studied. These results highlight influence of substituents on basicity this sites.

Since methoxyl group and fluor atom (F) have electroattractor effect, it could be argued that electron-attractor groups on 2-phenylbenzothiazole ring disadvantage the proton fixation on nitrogen $\mathrm{N} 1$ of benzothiazole ring.

\section{Acknowledgements}

Thanks to the colleagues of Organic Chemistry and Natural Substances laboratory of Felix Houphouët Boigny University for their advice.

\section{References}

[1] A. Ly, Current issues and future prospects in cancer prevention in developing countries, African Journal of Cancer, 2011, 3, 4, 268-272.

[2] J. M. Dangou, B.-H. Sambo, M. Moeti and A.-J. Diarra-Nama, Prévention et lutte contre le cancer dans la région africaine de
l'OMS: un appel à l'action, African Journal of Cancer, 2009, $1,1,56-60$.

[3] D. Moukassa, A. M. Boumba, C. F. Ngatali, A. Ebatetou, J. B. N. Mbon and J.-R. Ibara, Virus-Induced Cancers in Africa: Epidemiology and Carcinogenesis Mechanisms, Open Journal of Pathology, 2018, 8, 1-14.

[4] M. Ly, A. Ly, M. Rodrigues, Y. Loriot, M. Deberne, PP. Boudou-Rouquette, T. Bathily and D. Diallo, Cancer in Africa, a new health challenge. Examples of Mali and OncoMali, Bulletin du Cancer, 2010, 97, 8, 965-968.

[5] H. B. El-Serag, and K. L. Rudolph, Hepatocellular Carcinoma: Epidemiology and Molecular Carcinogenesis, Gastroenterology, 2007, 132, 7, 2557-2576.

[6] X. Peng, G. Xie, Z. Wang, H. Lin, T. Zhou, P. Xiang and Y. Zhao, SKLB-163, a new benzothiazole-2-thiol derivative, exhibits potent anticancer activity by affecting RhoGDI/JNK1 signaling pathway, Cell Death \& Disease, 2014, 5, 3, e1143.

[7] S. Ke, Y. Wei, Z. Yang, K. Wang, Y. Liang and L. Shi, Novel cycloalkylthiophene-imine derivatives bearing benzothiazole scaffold: Synthesis, characterization and antiviral activity evaluation, Bioorganic \& Medicinal Chemistry Letters, 2013, $23,18,5131-5134$.

[8] J. Zhang, Z. Q. Cheng, J. L. Song, H. R. Tao, K. Zhu, L. A. Muehlmann, C. S. Jiang and H. Zhang, Synthesis and biological evaluation of 2-(3-aminophenyl)-benzothiazoles as antiproliferative and apoptosis-inducing agents, Monatshefte Für Chemie-Chemical Monthly, 2018, 149, 11, 2093-2102.

[9] P. Linciano, C. Pozzi, L. D. Iacono, F. di PIsa, G. Landi, A. Bonucci, S. Gul, M. Kuzikov, B. Ellinger, G. Witt, N. Santarem, C. Baptista, C. Franco, C. B. Moraes, W. Müller, U. Wittig, R. Luciani, A. Sesenna, A. Quotadamo, S. Ferrari, I. Pöhner, A. C. Da-Silva, S. Mangani, L. Costantino, and M. P. Costi, Enhancement of Benzothiazoles as Pteridine Reductase-1 Inhibitors for the Treatment of Trypanosomatidic Infections, Journal of Medicinal Chemistry, 2019, 62, 8, 3989-4012.

[10] A. Trapania, A. Catalanoa, A. Caroccia, A. Carrieria, A. Mercurioa, A. Rosatoa, D. Mandracchiaa, G. Tripodob, B. I. P. Schiavonea, C. Franchinia, E. Mestoc, E. Schingaroc and F. Corboa, Effect of Methyl- $\beta$-Cyclodextrin on the antimicrobial activity of a new series of poorly water-soluble benzothiazoles, Carbohydrate Polymers, 2019, 207, 720-728.

[11] J. A. Johnson, G. Tora, Z. Pi, M. Phillips, X. Yin, R. Yang, L. Zhao, A. Y. Chen, D. S. Taylor, M. Basso, A. Rose, K. Behnia, J. Onorato, X. Q. Chen, L. M. Abell, H. Lu, G. Locke, C. Caporuscio, M. Galella, L. P. Adam, D. Gordon, R. R. Wexler and H. J. Finlay, Sulfonylated Benzothiazoles as Inhibitors of Endothelial Lipase, ACS Medicinal Chemistry Letters, 2018, 9, 12, 1263-1268.

[12] M. N. Noolvi, H. M. Patel, and M. Kaur, Benzothiazoles: search for anticancer agents, European journal of medicinal chemistry, 2012, 54, 447-462.

[13] C. G. Mortimer, G. Wells, J. P. Crochard, E. L. Stone, T. D. Bradshaw, M. F. G. Stevens and A. D. Westwell, Antitumor Benzothiazoles. 26. 2-(3, 4-Dimethoxyphenyl) -5fluorobenzothiazole (GW 610, NSC 721648), a Simple Fluorinated 2-Arylbenzothiazole, Shows Potent and Selective Inhibitory Activity against Lung, Colon, and Breast Cancer Cell Lines, Journal of Medicinal Chemistry, 2006, 49, 1, 179-185. 
[14] T. D. Bradshaw and A. D. Westwell, The development of the antitumour benzothiazole prodrug, Phortress, as a clinical candidate, Current medicinal chemistry, 2004, 11, 8, 10091021.

[15] I. Hutchinson, M. S. Chua, H. L. Browne, V. Trapani, T. D. Bradshaw, A. D. Westwell and M. F. G. Stevens, Antitumor Benzothiazoles. 14.1 Synthesis and in Vitro Biological Properties of Fluorinated 2- (4-Aminophenyl) benzothiazoles, Journal of Medicinal Chemistry, 2001, 44, 9, 1446-1455.

[16] E. Brantley, V. Patel, S. F. Stinson, V. Trapani, C. D. Hose, H. P. Ciolino, G. C. Yeh, J. S. Gutkind, E. A. Sausville and A. I. Loaiza-Pérez, The antitumor drug candidate 2-(4-amino-3methylphenyl) -5-fluorobenzothiazole induces NF- $\mathrm{KB}$ activity in drug-sensitive MCF-7 cells, AntiCancer Drugs, 2005, 16, 2, 137-142.

[17] S. H. Kok, R. Gambari, C. H. Chui, M. C. Yuen, E. Lin, R. S. Wong, F. Y. Lau, G. Y. Cheng, W. S. Lam, S. H. Chan, K. H. Lam, C. H. Cheng, P. B. Lai, M. W. Yu, F. Cheung, J. C. Tang and A. S. C. Chan, Synthesis and anticancer activity of benzothiazole containing phthalimide on human carcinoma cell lines, Bioorganic \& Medicinal Chemistry, 2008, 16, 7, 3626-3631.

[18] Y. Zhang, M. Chakraborty, C. G. Cerda-Smith, R. N. Bratton, N. E. Maurer, E. M. Senser, and M. Novak., Chemistry of Ring-Substituted 4- (Benzothiazol-2-yl) phenylnitrenium Ions from Antitumor 2- (4-Aminophenyl) benzothiazoles. Journal of Organic Chemistry, 2013, 78, 14, 6992-7000.

[19] T. D. Bradshaw, D. F. Shi, R. J. Schultz, K. D. Paull, L. Kelland, A. Wilson, C. Garner, H. H. Fiebig, S. Wrigley and M. F. G. Stevens, Influence of 2-(4-aminophenyl) benzothiazoles on growth of human ovarian carcinoma cells in vitro and in vivo, British Journal of Cancer, 1998, 78, 4, 421429.

[20] A. Wallqvist, J. Connelly, E. A. Sausville, D. G. Covell, and A. Monks, Differential Gene Expression as a potential classifier of 5F-203 Sensitive and Insensitive Cell Lines, Molecular Pharmacology, 2006, 69, 3, 737-748.

[21] S. Aiello, G. Wells, E. L. Stone, H. Kadri, R. Bazzi, D. R. Bell, M. F. G. Stevens, C. S. Matthews, T. D. Bradshaw and A. D. Westwell, Synthesis and Biological Properties of Benzothiazole, Benzoxazole, and Chromen-4-one Analogues of the Potent Antitumor Agent 2-(3, 4-Dimethoxyphenyl) -5fluorobenzothiazole (PMX 610, NSC 721648) (1). Journal of Medicinal Chemistry, 2008, 51, 16, 5135-5139.

[22] C. O. Leong, M. Suggitt, D. J. Swaine, M. C. Bibby, M. F. G. Stevens, and T. D. Bradshaw, In vitro, in vivo, and in silico analyses of the antitumor activity of 2-(4-amino-3methylphenyl) -5-fluorobenzothiazoles, Molecular Cancer Therapeutics, 2004, 3, 12, 1565-1575.

[23] T. D. Bradshaw, E. L. Stone, V. Trapani, C. O. Leong, C. S. Matthews, R. Poele, M. F. G. Stevens, Mechanisms of acquired resistance to 2-(4-Amino-3-methylphenyl) benzothiazole in breast cancer cell lines, Breast Cancer Research and Treatment, 2008, 110, 1, 57-68.

[24] M. S. Chua, E. Kashiyama, T. D. Bradshaw, S. F. Stinson, E. Brantley, E. A. Sausville, and M. F. Stevens, Role of CYP1A1 in Modulation of Antitumor Properties of the Novel Agent 2(4-Amino-3-methylphenyl) benzothiazole (DF 203, NSC 674495) in Human Breast Cancer Cells, Cancer Research, 2000, 60, 5196-5203.
[25] B. S. Tan, K. H. Tiong, A. Muruhadas, N. Randhawa, H. L. Choo, T. D. Bradshaw, M. F. G. Stevens and C. O. Leong, CYP2S1 and CYP2W1 mediate 2-(3, 4-dimethoxyphenyl)-5fluorobenzothiazole (GW-610, NSC 721648) sensitivity in breast and colorectal cancer cells, Molecular Cancer Therapeutics, 2011, 10, 1982-1992.

[26] A. D. Becke, Density-functional thermochemistry. V. Systematic optimization of exchange-correlation functionals, Journal of chemical physics, 1997, 107, 20, 8554-8560.

[27] R. Bauernschmitt and R. Ahlrichs, Stability analysis for solutions of the closed shell Kohn-Sham equation, Journal of chemical physics, 1996, 104, 22, 9047-9052.

[28] C. Lee, W. Yang, and R. G. Parr, Development of the ColleSalvetti correlation-energy formula into a functional of the electron density, Physical review B, 1988, 37, 2, 785-789.

[29] A. D. Becke, Density-functional thermochemistry. I. The effect of the exchange-only gradient correction, Journal of chemical physics, 1993, 98, 7, 5648-5652.

[30] M. J. Frisch, G. W. Trucks, H. B. Schlegel, G. E., Scuseria, M. A. Robb, J. R. Cheeseman, J. A. Montgomery, Jr., T. Vreven, K., N. Kudin, J. C. Burant, J. M. Millam, S. S. Iyengar, J. Tomasi, V. Barone, B., Mennucci, M. Cossi, G. Scalmani, N. Rega, G. A. Petersson, H. Nakatsuji, M., Hada, M. Ehara, K. Toyota, R. Fukuda, J. Hasegawa, M. Ishida, T. Nakajima, Y. Honda, O. Kitao, H. Nakai, M. Klene, X. Li, J. E. Knox, H. P. Hratchian, J., B. Cross, C. Adamo, J. Jaramillo, R. Gomperts, R. E. Stratmann, O. Yazyev, A. J. Austin, R. Cammi, C. Pomelli, J. W. Ochterski, P. Y. Ayala, K., Morokuma, G. A. Voth, P. Salvador, J. J. Dannenberg, V. G. Zakrzewski, S., Dapprich, A. D. Daniels, M. C. Strain, O. Farkas, D. K. Malick, A. D., Rabuck, K. Raghavachari, J. B. Foresman, J. V. Ortiz, Q. Cui, A. G. Baboul, S. Clifford, J. Cioslowski, B. B. Stefanov, G. Liu, A. Liashenko, P. Piskorz, I., Komaromi, R. L. Martin, D. J. Fox, T. Keith, M. A. Al-Laham, C. Y. Peng, A., Nanayakkara, M. Challacombe, P. M. W. Gill, B. Johnson, W. Chen, M. W., Wong, C. Gonzalez, et J. A. Pople, Gaussian, Inc., Pittsburgh PA. Gaussian 03, Revision A.1, 2003.

[31] E. Cancès, B. Mennucci, and J. Tomasi, A new integral equation formalism for the polarizable continuum model: Theoretical background and applications to isotropic and anisotropic dielectrics, Journal of chemical physics, 1997, $107,8,3032-3041$.

[32] G. E. Scuseria, T. J. Lee, R. J. Saykally, and H. F. Schaefer, Nitrogen quadrupole coupling constants for $\mathrm{HCN}$ and $\mathrm{H}_{2} \mathrm{CN}^{+}$: Explanation of the absence of fine structure in the microwave spectrum of interstellar $\mathrm{H}_{2} \mathrm{CN}^{+}$, Journal of chemical, 1986, 84, $10,5711-5714$

[33] M. C. Rezende, A theoretical HSAB study of the acidity of carbon acids $\mathrm{CH} 3 \mathrm{Z}$, Journal of the Brazilian Chemical Society, 2001, 12, 1, 73-80.

[34] C. Møller and M. S. Plesset, Note on an approximation treatment for many-electron systems, Physical review, 1934, $46,7,618-622$.

[35] R. G. Parr, R. A. Donnelly, M. Levy, and W. E. Palke, Electronegativity: The density functional viewpoint, Journal of Chemical Physics, 1978, 68, 8, 3801-3807.

[36] C. Morell, A. Grand, and A. Toro-Labbé, New dual descriptor for chemical reactivity, Journal of Physical Chemistry A, 2005, 109, 1, 205-212. 
[37] P. Bultinck, D. Clarisse, PP. W. Ayers, and R. Carbo-Dorca, The Fukui matrix: a simple approach to the analysis of the Fukui function and its positive character, Physical Chemistry Chemical Physics, 2011, 13, 6110-6115.

[38] J. Melin, PP. W. Ayers, and J. V. Ortiz, Removing electrons can increase the electron density: a computational study of negative Fukui functions, Journal of Physical Chemistry A, 2007, 111, 40, 10017-10019.

[39] H. Eljazouli, H. Kabli, T. Atbir, M. Elamine, and A. Albourine, Protonation of Uracil, Thymin and 5Halogénouracil Examined at the Isolated State. Calculation of the Protonic Affinitys by the AM1 Method, Physical \& Chemical News, 2007, 34, 97-104.

[40] M. D. Liptak, K. C. Gross, PP. G. Seybold, S. Feldgus, and G. C. Shields, Absolute $\mathrm{pK}_{\mathrm{a}}$ Determinations for Substituted Phenols, Journal of the American Chemical Society, 2002, $124,22,6421-6427$.

[41] B. R. Scott, G. L. Dorn, E. Käfer, and R. Stafford, Aspergillus nidulans: systems and results of tests for induction of mitotic segregation and mutation. II. Haploid assay systems and overall response of all systems. A report of the U.S. EPA Gene-Tox Program, Mutation Research, 1982, 98, 1, 49-94.
[42] M. Belletête, J.-F. Morin, M. Leclerc, and G. Durocher, A Theoretical, Spectroscopic, and Photophysical Study of 2, 7Carbazolenevinylene-Based Conjugated Derivatives, Journal of Physical Chemistry A, 2005, 109, 31, 6953-6959.

[43] J. Aihara, Reduced HOMO-LUMO gap as an index of kinetic stability for polycyclic aromatic hydrocarbons, Journal of Physical Chemistry A, 1999, 103, 37, 7487-7495.

[44] A. A. Shabana, I. S. Butler, D. F. R. Gilson, B. J. Jean-Claude, Z. S. Mouhri, M. M. Mostafa, and S. I. Mostafa, Synthesis, characterization, anticancer activity and DNA interaction studies of new 2-aminobenzothiazole complexes; crystal structure and DFT calculations of $\left[\mathrm{Ag}(\mathrm{Habt})_{2}\right] \quad \mathrm{ClO}_{4}$, Inorganica Chimica Acta, 2014, 423, 242-255.

[45] C. O. Leong, M. Gaskell, E. A. Martin, R. T. Heydon, P. B. Farmer, M. C. Bibby, P. A. Cooper, J. A. Double, T. D. Bradshaw and M. F. G. Stevens, Antitumour 2(4aminophenyl) benzothiazoles generate DNA adducts in sensitive tumour cells in vitro and in vivo, British Journal of Cancer, 2003, 88, 3, 470-477.

[46] R. K. Roy, S. Pal, and K. Hirao, On non-negativity of Fukui function indices, Journal of chemical physics, 1999, 110, 17, $8236-8245$ 